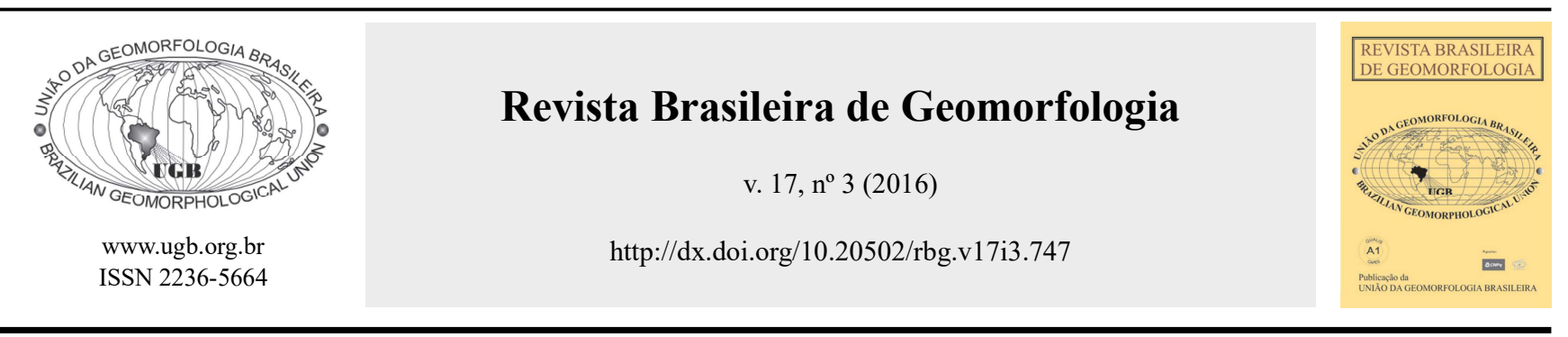

\title{
CARACTERIZAÇÃO MORFOSSEDIMENTAR DOS EFEITOS DO EVENTO DE FLUXO DE SEDIMENTOS DE 2009 NA VILA DE SÃO VICENTE, CACHOEIRO DE ITAPEMIRIM - ES
}

\section{MORPHO-SEDIMENTARY CHARACTERIZATION OF THE 2009 SEDIMENT FLOW EVENT EFFECTS IN SÃO VICENTE VILLAGE, CACHOEIRO DE ITAPEMIRIM - ES}

\author{
Cláudio Eduardo Lana \\ Departamento de Geologia, Universidade Federal de Ouro Preto \\ Campus Morro do Cruzeiro, S/N, Ouro Preto, Minas Gerais. CEP 35.400-000. Brasil \\ Email: claudiolana@degeo.ufop.br \\ Raiane Soares de Macedo \\ Instituto de Geociências, Universidade Federal de Minas Gerais \\ Av. Antônio Carlos, 6.627, Belo Horizonte, Minas Gerais. CEP 31.270-901. Brasil \\ Email:raiane_vzp@hotmail.com
}

Izadora Rodrigues Gomes

Departamento de Geologia, Universidade Federal do Espírito Santo Alto Universitário, S/N, Alegre, Espírito Santo. CEP 29.500-000. Brasil

Email: izadoragomesg@hotmail.com

Fabrícia Benda de Oliveira

Departamento de Geologia, Universidade Federal do Espírito Santo Alto Universitário, S/N, Alegre, Espírito Santo. CEP 29.500-000. Brasil

Email:fabricia.oliveira@ufes.br

Informações sobre o Artigo

Recebido (Received):

08/03/2016

Aceito (Accepted):

$22 / 04 / 2016$

\section{Palavras-chave:}

Leque Aluvial; Evolução Morfossedimentar; Faciologia.

Keywords:

Alluvial Fan; Morphosedimentary Evolution; Faciology.

\section{Resumo:}

Durante o verão de 2009 a região Sul do Espírito Santo foi assolada por fluxos de sedimentos ao longo de suas vertentes mais íngremes. A vila de São Vicente, distrito de Cachoeiro de Itapemirim, se destacou neste contexto, tendo sido palco de deslizamentos de encostas e sistemática remobilização de depósitos pré-existentes, cujo efeito foi o soterramento parcial do distrito por um corpo sedimentar de proporções quilométricas. O presente trabalho define tecnicamente os limites espaciais da corrida e também classifica a entidade morfossedimentar gerada. Para tanto, lança-se mão de técnicas cartográficas e estratigráficas, as quais são integradas e confrontadas ao contexto geológico regional bem como a modelos análogos presentes na literatura especializada. Com a realização do estudo pretende-se fornecer as bases para o estabelecimento de critérios adequados de uso e ocupação na região, bem como para estudos mais aprofundados do fenômeno, envolvendo técnicas de alcance tridimensional como as geofísicas. 
Abstract:

Several sediment flows were observed in the steeper hill slopes of southern Espírito Santo State during 2009 summer. Throughout this event a kilometric sediment body partially buried the village of São Vicente, municipality of Cachoeiro de Itapemirim. Landslides and the relocation of ancient sediment deposits started the process. The technical definition of the mass flow physical limits as well as the morpho-sedimentary classification of the sediment body is presented herein. In order to achieve these goals, cartographic and stratigraphic techniques were applied and the regional geological setting oriented integrated analysis of the results. All of the data was compared with analog models found in the literature. This analysis can act as a guide for further tridimensional investigations, e.g. with a geophysical approach, and for more rational land use strategies.

\section{Introdução}

O município de Cachoeiro de Itapemirim, localizado no sul do Espírito Santo, é dotado de uma paisagem particularmente rugosa, em função da clara sucessão entre elementos morfológicos de cota e geometria variável. De acordo com King (1956), as cumeadas regionais são produto dos ciclos de denudação Velhas e Paraguaçu, relacionados respectivamente a eventos erosivos terciários (sic) e quaternários.

Em nível de maior detalhe e conforme classificação de Gatto et al. (1983), a região se insere geomorfologicamente no contexto dos "Patamares Escalonados do Sul Capixaba" os quais, por sua vez, são subdivididos em três níveis. A área-alvo deste trabalho está alojada no nível intermediário, cujas características mais marcantes são formas alongadas e retilíneas, além de vales ocupados por rios quase sempre colmatados pelo material sedimentar proveniente do topo.

Os mesmos autores constatam ainda que as vertentes se apresentam na forma de rampas, produzidas por movimentos de massa. Esta interpretação é corroborada por sistemáticas remobilizações de depósitos de fundo de vale oriundos de fluxos de sedimentos provenientes das encostas e leques aluviais afetados por deslizamentos, como ocorrido no verão de 2009. Dentre os elementos morfossedimentares envolvidos, destaca-se aqui um corpo de dimensões quilométricas, em cuja porção central se encontra a vila de São Vicente, distrito de Cachoeiro de Itapemirim, cuja localização e contexto geológico podem ser observados nas figuras 1 e 2 .

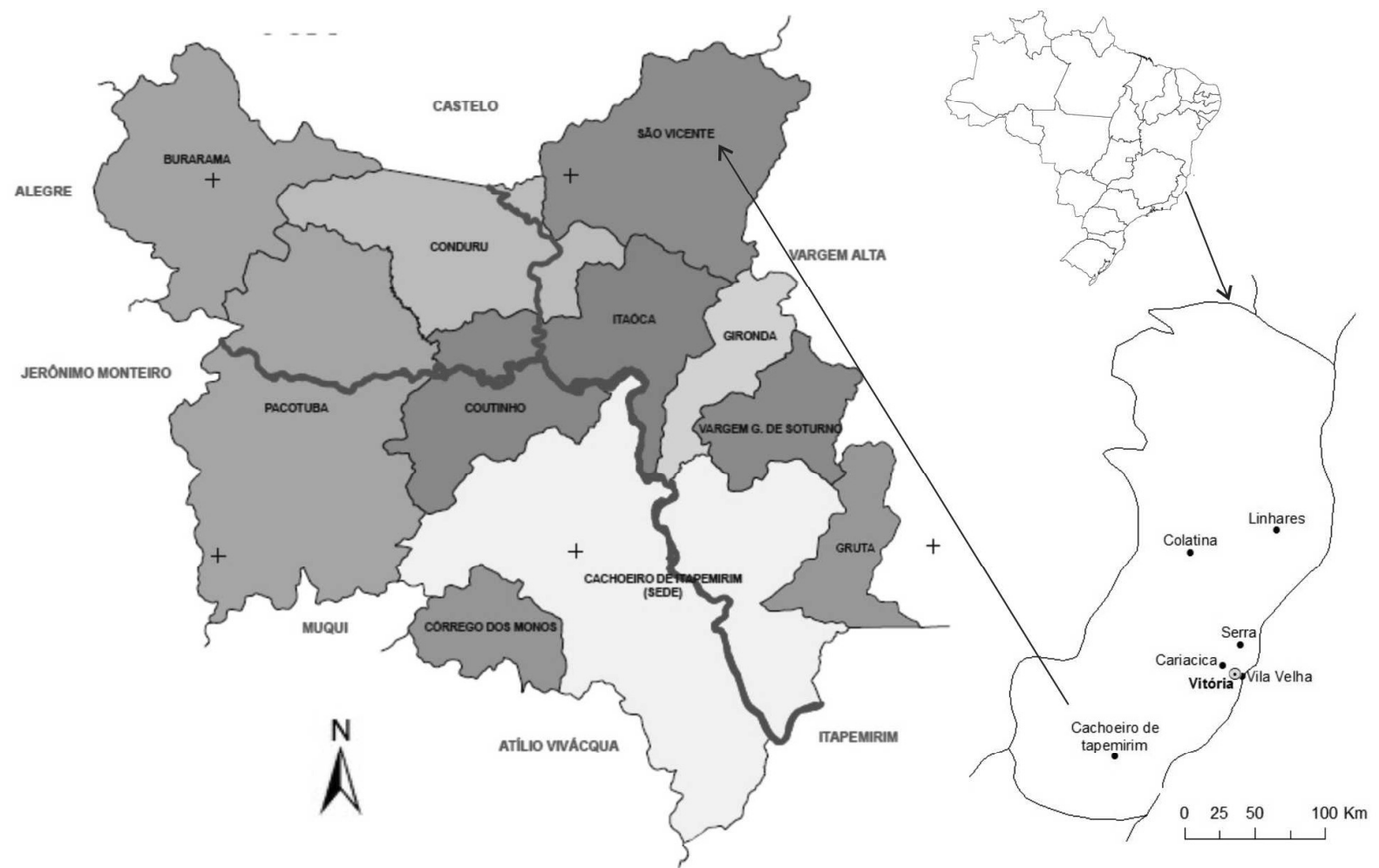

Figura 1 - Localização da área de trabalho. No canto direito tem-se o posicionamento de Cachoeiro de Itapemirim em relação ao estado do Espírito Santo. À esquerda é apresentada a divisão política do municipio, apontando-se o distrito de São Vicente. Adaptação elaborada a partir de figura disponivel em http://www.cachoeiro.es.gov.br. 


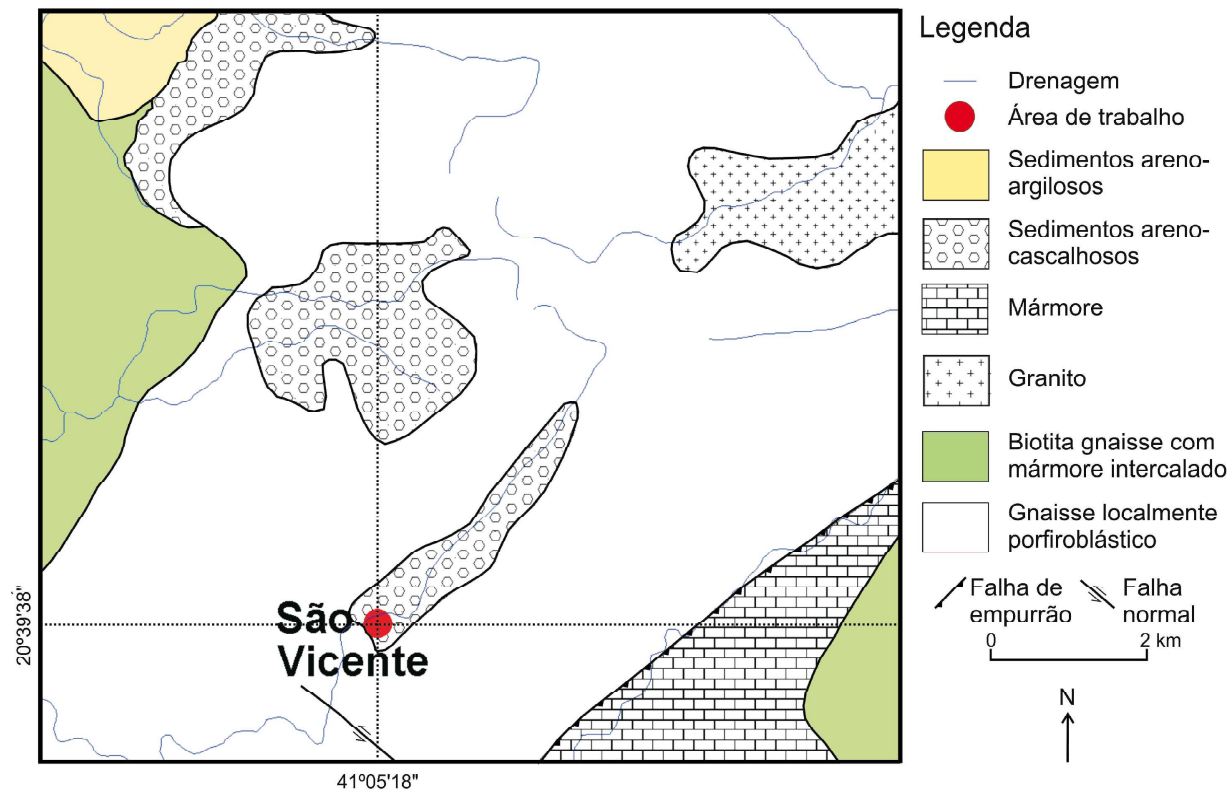

Figura 2 - Mapa geológico da área de São Vicente. Compilado a partir da folha Cachoeiro de Itapemirim em escala 1:100.000 (CPRM, 1993).

Durante a remobilização de 2009, o transporte sedimentar se deu na forma de um evento extremo, resultante de chuvas intensas e concentradas. Sua principal característica foi a corrida repentina de uma massa de alta viscosidade, contendo material heterogêneo, variando de lama a clastos multimétricos. A energia e volume da corrente acarretou uma série de prejuízos materiais, destacando-se a destruição de obras civis e o soterramento da parte baixa do distrito por uma coluna sedimentar de até 2 metros de espessura.

Ao contrário de fluxos de detritos análogos, verificados há poucos anos nos estados do Rio de Janeiro e Santa Catarina, felizmente o evento extremo de São Vicente não resultou na perda de vidas humanas. Provavelmente por este motivo as atenções da mídia e do meio acadêmico não tenham se voltado para a região, com exceção dos trabalhos de divulgação apresentados por Lana \& Cerqueira (2009), Lana et al. (2011) e Macedo et al. (2012). Apesar disso, sabe-se que os fluxos de detritos são fenômenos reincidentes e de baixa previsibilidade. Estes fatos, somados às grandes proporções do evento de 2009 e ao padrão desordenado de ocupação da área faz da ausência de vítimas um mero fruto do acaso.

Investigar a natureza dos fenômenos envolvidos e definir tecnicamente a abrangência espacial dos efeitos do evento extremo, a partir da morfologia resultante, é de fundamental importância para subsidiar projetos que visem ao uso e ocupação adequados do solo, à identificação de áreas de risco/susceptibilidade similares e à minimização dos impactos advindos de corridas futuras.

O presente trabalho tem como objetivo caracterizar a morfossedimentação de corpo resultante de evento extremo ocorrido no ano de 2009 em São Vicente, analisando suas subclassificações conforme as variações das características topográficas e faciológicas predominantes. Para tanto, procurou-se contextualizar topograficamente as imediações do distrito, com ênfase nos limites da área de atuação do evento extremo; analisar a possibilidade de influência de fatores litoestruturais sobre a ocorrência do evento; definir diferentes domínios morfossedimentares por meio da identificação, descrição e interpretação de fácies distintivas; e classificar o corpo morfossedimentar, incluindo possíveis subclassificações, de acordo com a literatura pertinente.

\section{Materiais e Métodos}

A metodologia adotada para execução do trabalho é sintetizada nos itens a seguir.

\subsection{Trabalho de Campo de Reconhecimento}

Esta etapa foi realizada poucos dias após a ocorrência do evento, com o apoio de um funcionário da prefeitura de Cachoeiro de Itapemirim, a quem coube a comunicação do ocorrido à Universidade Federal do Espírito Santo, na busca de parcerias no sentido da investigação do fenômeno. Como suporte a esta etapa, foram analisadas imagens do Google Earth ${ }^{\circledR}$. Ao longo da visita de campo os limites da área de influência da corrida de massa foram identificados de forma expedita e tiveram suas coordenadas geográficas determinadas com o auxílio de um GPS de navegação. Esses dados foram de suma importância na etapa de determinação preliminar do contexto geomorfológico da área de trabalho. 


\subsection{Determinação Preliminar do Relevo da Área}

O contexto geomorfológico foi preliminarmente determinado no intuito de fornecer subsídios às primeiras interpretações sobre a natureza da corrida de massa e também orientar as etapas de campo subsequentes. Nesta etapa, além da impressão visual e das coordenadas adquiridas na etapa anterior, foram utilizadas imagens de radar SRTM (Shuttle Radar Topography Mission - Miranda, 2005), a partir das quais foram gerados modelos digitais de elevação (MDE) e perfis topográficos com o auxílio do software Global Mapper ${ }^{\mathrm{TM}}$.

\subsection{Compilação Geológica}

A geologia regional foi compilada a partir da base disponível na maior escala para a região: Folha Cachoeiro de Itapemirim em escala 1:100.000 (CPRM, 1993). Esta compilação visou à identificação de características e feições litoestruturais que poderiam condicionar a configuração do relevo regional e, consequentemente, a intensidade dos processos erosivos e dos fluxos sedimentares.

\subsection{Cartografia Planialtimétrica}

Esta etapa consistiu no levantamento topográfico da área de trabalho em escala 1:10.000 e aquisição de dados de elevação e posicionamento de 20 pontos de alta relevância. Esses pontos foram escolhidos por apresentarem excelentes perfis de fácies sedimentares, por estarem contidos em zonas de variação abrupta de declividade e/ou em áreas limítrofes do corpo morfossedimentar (Figura 3). O instrumental utilizado nesta fase foi um GPS Topográfico Magellan ProMark 3.

Adotou-se o método de coleta estático, por produzir dados mais precisos e confiáveis, sendo a confiabilidade dos dados dependente da extensão de observação durante a coleta. Após alguns testes, o tempo de cinco minutos foi aceito como satisfatório.

$\mathrm{Na}$ etapa de pós-processamento, os dados foram carregados do receptor GPS a um computador. O software Ashtech Solutions foi utilizado para a correção dos dados, de acordo com a base de Vitória (ES). Após o processamento, os dados puderam ser usados em sistemas de informação geográfica (SIG), viabilizando a produção de mapas e modelos digitais do terreno.

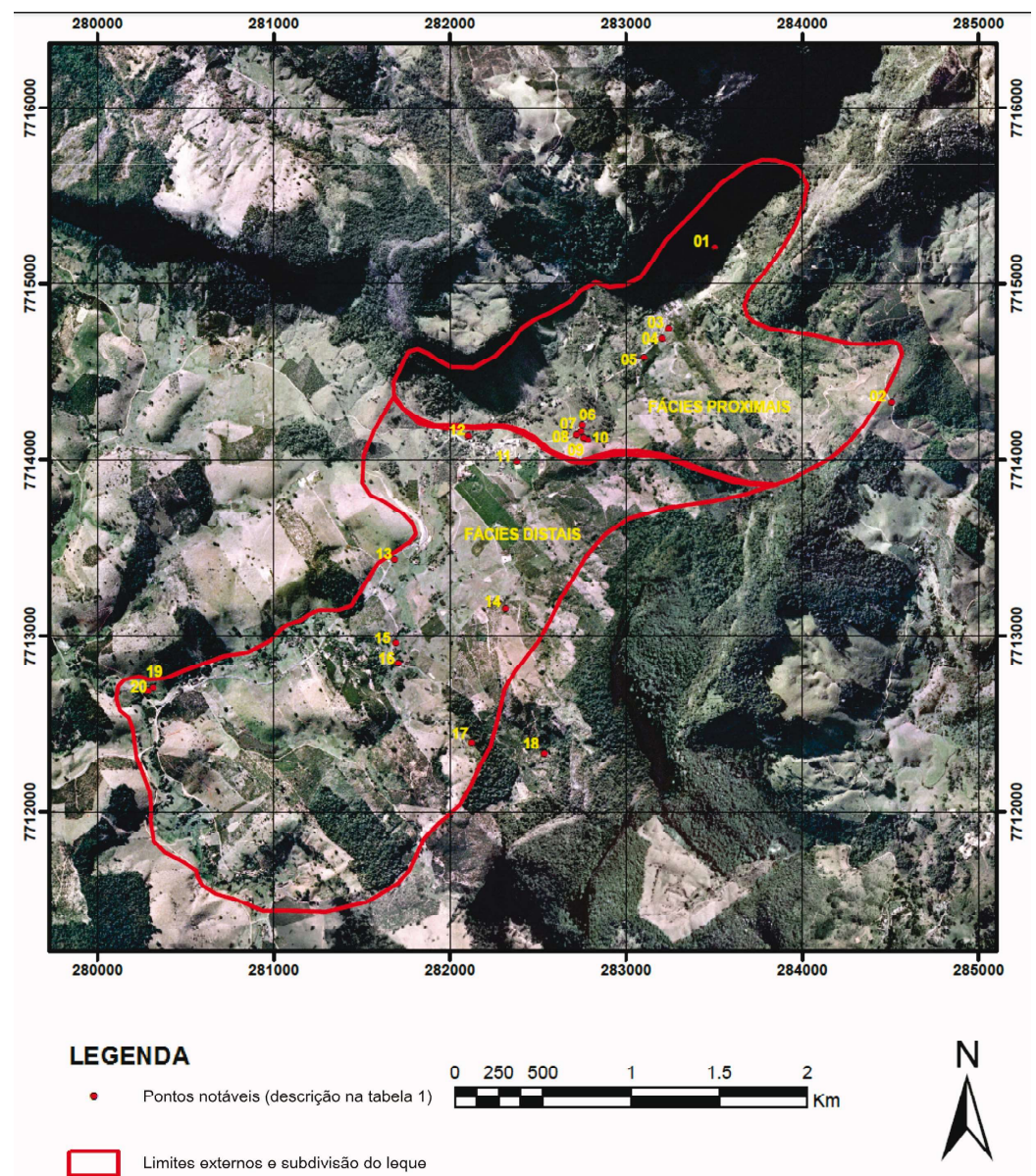

Figura 3 - Delimitação do leque de São Vicente e individualização das zonas de fácies distal e proximal. Dados lançados sob um recorte do Google Earth ${ }^{\circledR}$. A descrição dos elementos de destaque nos pontos notáveis é apresentada na tabela 1. 


\subsection{Levantamento de Fácies Sedimentares}

Nesta etapa procurou-se identificar visualmente as fácies sedimentares presentes nos cortes de estrada, margens de drenagem e encostas. A sua descrição foi efetuada por meio de lupa de mão e cartela granulométrica, para posterior enquadramento em um dos modelos de fácies de Walker (1984) e consequente interpretação pormenorizada dos subambientes deposicionais imperantes em diferentes posições da entidade morfossedimentar investigada.

\subsection{Tratamento de Dados e Classificação}

Esta fase foi realizada em laboratório e consistiu na reunião de todos os dados obtidos, elaboração de modelos tridimensionais e mapas da área de trabalho. Além disso, foram analisadas conjuntamente as fácies sedimentares descritas, o que culminou na classificação do corpo morfossedimentar em questão, além dos refinamentos possíveis.

\section{Resultados}

Com base nas observações do trabalho de campo de reconhecimento e na análise da área, a partir do Google Earth $^{\circledR}$ e do modelo tridimensional SRTM, percebeu-se que o corpo morfossedimentar investigado corresponde a um leque aluvial. De acordo com as definições de Harvey et al. (2005), Miall (1990) e Assine (2008), algumas características notáveis em campo e escritório corroboram esta interpretação, tais como o confinamento orográfico da área, o decréscimo abrupto na declividade das cabeceiras para a base (Figura 4), a existência de um fluxo fluvial perene e a presença de pacotes sedimentares associados a fluxos de detritos (Figura 5).
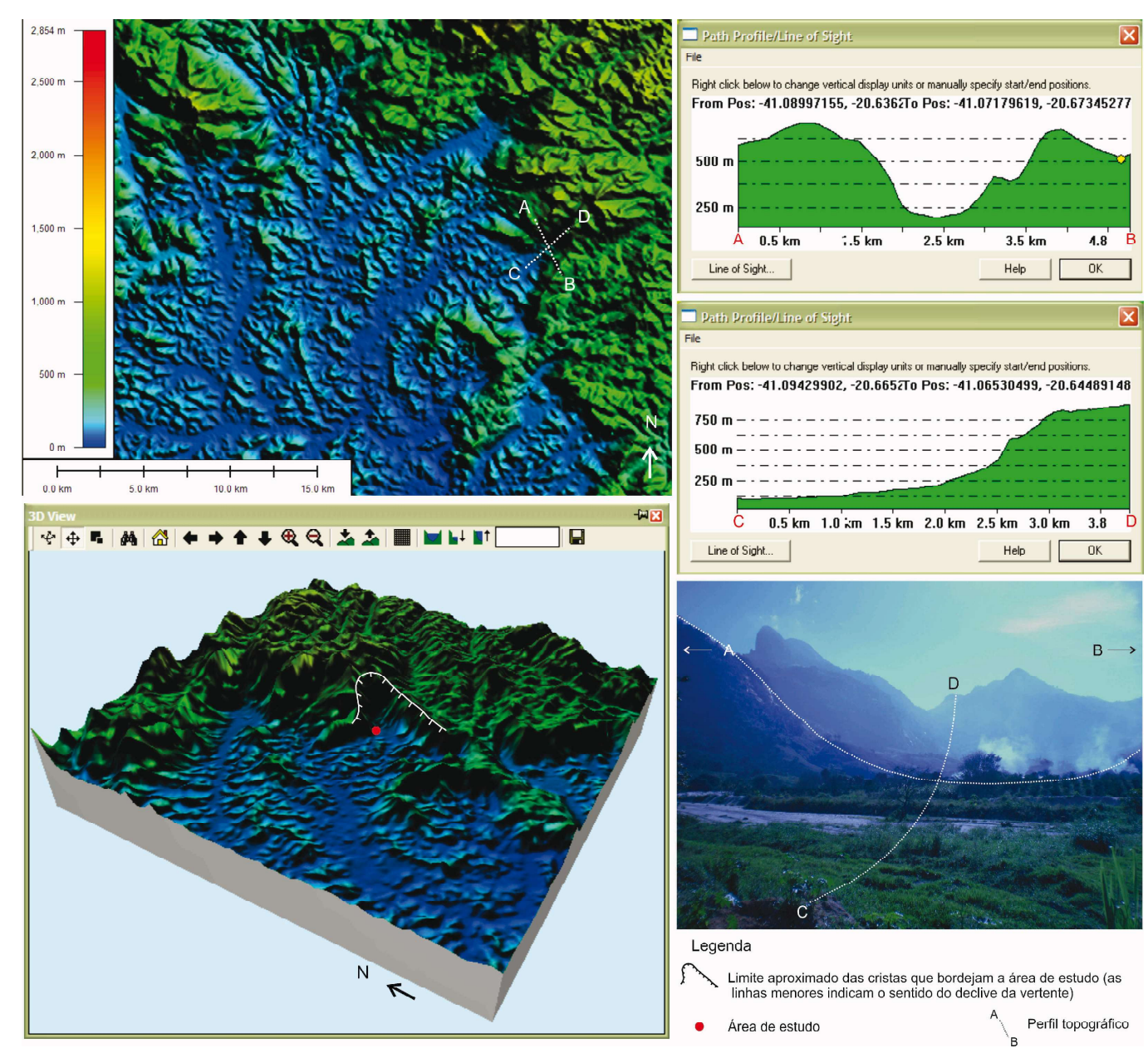

Figura 4 - Modelos tridimensionais de elevação preliminares da região de São Vicente, gerados a partir de dados SRTM (Miranda, 2005). Destaque para o leito fluvial colmatado por sedimento arenoso (porção central da foto), para o confinamento transversal da área (perfil $A-B)$ e para a seção longitudinal em rampa de declividade abruptamente decrescente (perfil $C-D$ ). 

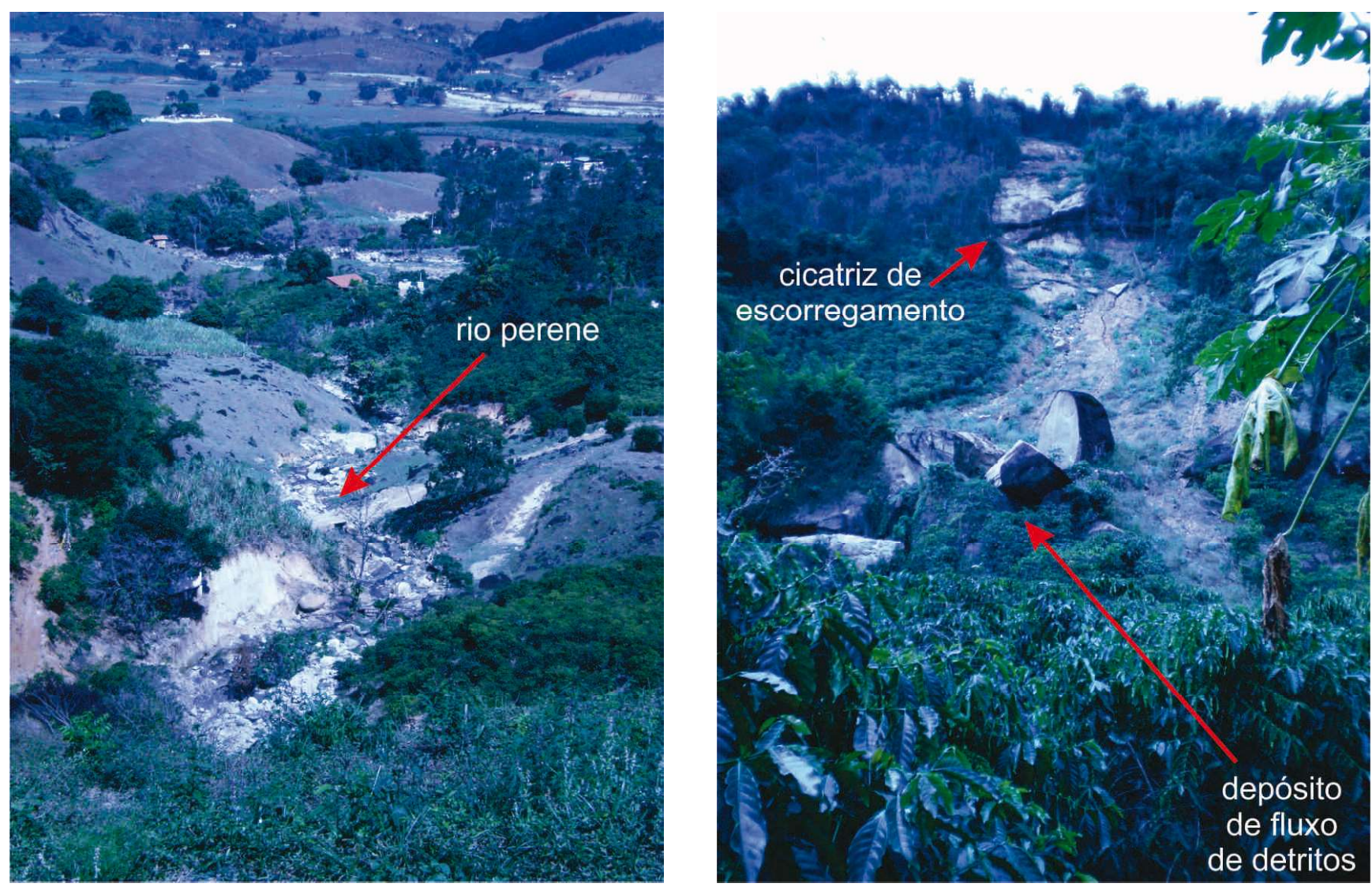

Figura 5 - Fotografias da região de São Vicente ilustrando a presença de um canal fluvial perene (esquerda) e cicatriz de escorregamento e depósito de fluxo de detritos (direita).

De acordo com o mapa geológico da região, não existem estruturas geológicas frágeis cartografadas especificamente na área do leque aluvial (Figura 2). Entretanto, dada a escala de baixo detalhe, é possível inferir que as falhas transcorrente e de empurrão, respectivamente localizadas a sul e leste da área de trabalho, sejam exemplares de famílias de diáclases, com correspondentes subparalelos, os quais eventualmente alcançariam o distrito de São Vicente e se ocultariam sob os sedimentos do próprio leque aluvial. Esta suspeita se reforça pela presença das linhas de cumeada NNE-SSW e NE-SW, que confinam o leque a leste e noroeste (Figura 4) e são subparalelas ao traço da falha de empurrão documentada na figura 2. Além da conformação morfoestrutural da área, a reativação das supostas estruturas poderia potencializar de alguma maneira $o$ papel das persistentes chuvas de 2009 na disparada dos movimentos de massa.

A tabela 1 descreve os pontos registrados no levantamento planialtimétrico apresentado na figura 6 .
Os pontos mais notáveis são ilustrados pelas fotografias que compõem as figuras 7 e 8 . Como previamente mencionado, os dados foram lançados também sobre um recorte do Google Earth ${ }^{\circledR}$ (Figura 3), onde as relações de sombreamento permitem notar o confinamento das cabeceiras do leque aluvial, sobretudo em sua extremidade NW. A partir da base topográfica que compõe a figura 6 , foi possível calcular sua dimensão longitudinal em torno de $5 \mathrm{~km}$ e a declividade média da porção proximal da ordem de $15^{\circ}$. A simples análise visual da equidistância entre as curvas de nível evidencia a abrupta redução da declividade quando se atinge a porção distal.

Uma etapa de campo foi realizada especificamente para descrição de perfis de fácies sedimentares presentes em barrancos, cortes de estrada e margens da drenagem perene. Ainda na etapa de levantamento topográfico, já havia sido notada uma clara diferenciação faciológica entre os pacotes sedimentares descritos na zona de maior e menor declividade. Seguindo as proposições de Miall (1978), este contraste 
Tabela 1: Descrição dos pontos adotados no levantamento planialtimétrico.

\begin{tabular}{c|c}
\hline Ponto & Descrição \\
\hline 1 & Afloramento rochoso / zona de escorregamento / fluxo de detritos. \\
\hline 2 & Divisor de águas. Limite superior do leque aluvial. \\
\hline 3 & Fácies proximal de leque aluvial. \\
\hline 4 & Fácies proximal de leque aluvial. \\
\hline 5 & Fácies proximal de leque aluvial. \\
\hline 7 & Fácies proximal de leque aluvial. \\
\hline 8 & Fácies proximal de leque aluvial. \\
\hline 9 & Fácies proximal de leque aluvial. \\
\hline 10 & Fácies proximal de leque aluvial. \\
\hline 11 & Fácies proximal de leque aluvial. \\
\hline 13 & Fácies distal de leque aluvial. \\
\hline 14 & Fácies distal de leque aluvial. \\
\hline 15 & Fácies distal de leque aluvial. \\
\hline 16 & Fácies fluvial. \\
\hline 17 & Fácies fluvial. \\
\hline 18 & Fácies distal de leque aluvial. \\
\hline 19 & Rocha sã. \\
\hline 20 & Fácies distal de leque aluvial. \\
\hline & Fácies distal de leque aluvial. \\
\hline
\end{tabular}

faciológico, aliado a questões topográficas, orientou o traçado da linha que divide o leque nas porções onde predominam declives acentuados com fácies cascalhosas (proximal) e declives suaves a nulos com fácies arenosas ou lamosas (distal), conforme apresentado nas figuras 3 e 6 .

As três fotografias que compõem a figura 7 ilustram, em sentido anti-horário, o cenário morfológico de três importantes áreas do leque aluvial de São Vicente: as cabeceiras, dominadas por uma topografia íngreme e depósitos associados a fluxos de detritos; a planície aluvial, com topografia suave e sedimentação predominantemente arenosa e o canal fluvial entrelaçado que recebe e retrabalha a contribuição sedimentar de montante. A posição dos elementos geomorfológicos ilustrados é esquematicamente apontada no modelo deposicional proposto por Rust (1984) para a Formação Cannes de Roche (Carbonífero do Canadá).

A figura 8 traz exemplos de fácies notáveis, distintivas de leques aluviais, descritas na região de São Vicente. Assim como na figura 7, as letras indicam o código das fácies (descrição na tabela 2), enquanto os números remetem à posição dos pontos, conforme já apresentado nas figuras 3 e 6 e tabela 1. A distribuição longitudinal dos pontos fotografados é apontada no perfil esquemático de leques aluviais de Rust \& Koster (1984). 


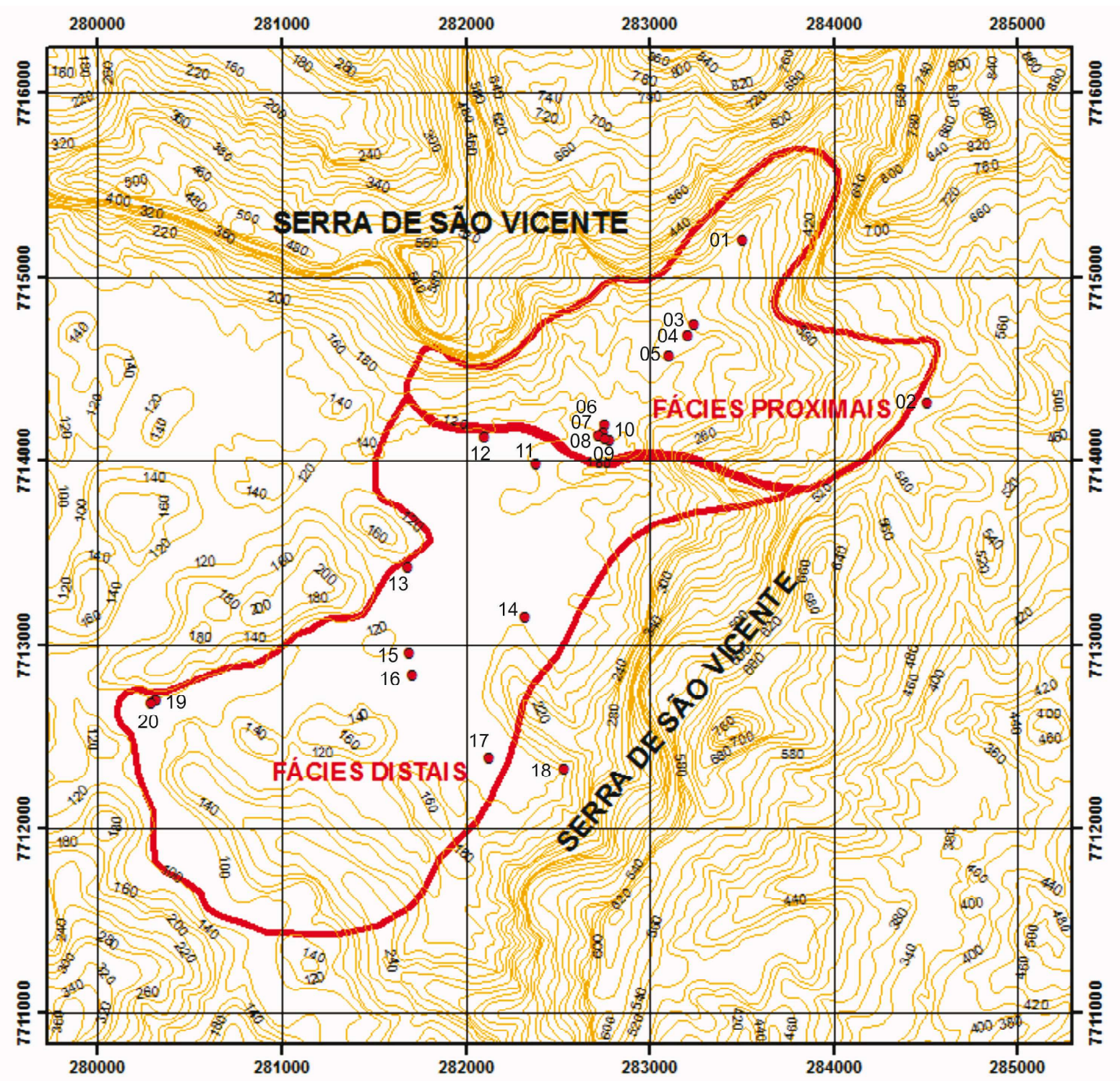

\section{LEGENDA}

- Pontos notáveis (descrição na tabela 1)

Curvas de nível

Limites externos e subdivisão do leque

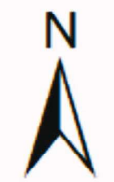

Figura 6 - Delimitação do leque de São Vicente e individualização das zonas de fácies distal e proximal. A numeração dos pontos é a mesma apresentada na figura 3. Topografia compilada a partir da carta topográfica Cachoeiro do Itapemirim em escala 1:50.000 (IBGE, 1978).

Além dos depósitos de fluxo de detritos, preservados na porção proximal do leque (Figuras 5 e 7), outro processo sedimentar distintivo de movimentos de massa, denominado fluxo fluidificado (Lowe, 1979), também gerou notáveis depósitos na porção intermediária do leque de São Vicente, sendo os mesmos mar- cados por nítida granodecrescência ascendente (finning upward) (Figura 9). Como esses depósitos são associados a corridas repentinas sem retrabalhamento aluvial significativo, sua presença sugere que a prevalência dos processos sedimentares gravitacionais sobre os fluviais não está restrita aos fluxos de detritos das cabeceiras. 
Caracterização Morfossedimentar dos Efeitos do Evento de Fluxo de Sedimentos de 2009 na Vila de São Vicente
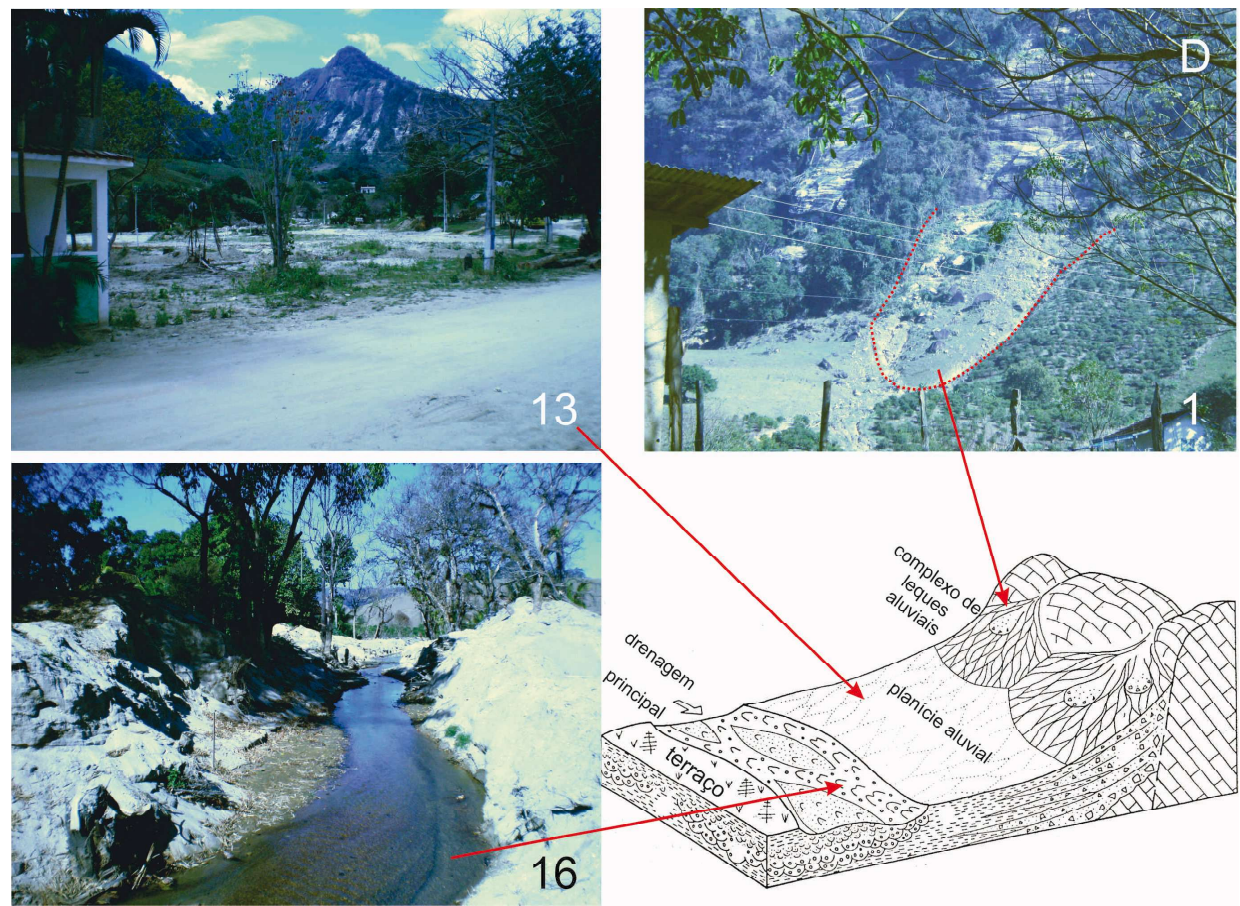

Figura 7 - Ilustração de elementos geomorfológicos típicos de leques aluviais identificados em São Vicente, incluindo um corpo de fluxo de detritos (D). As áreas fotografadas são vinculadas às suas posições no bloco-diagrama esquemático de Rust (1984). Os números têm equivalência com os pontos mais notáveis descritos na tabela 1. Sua distribuição espacial pode ser conferida nas figuras 3 e 6.

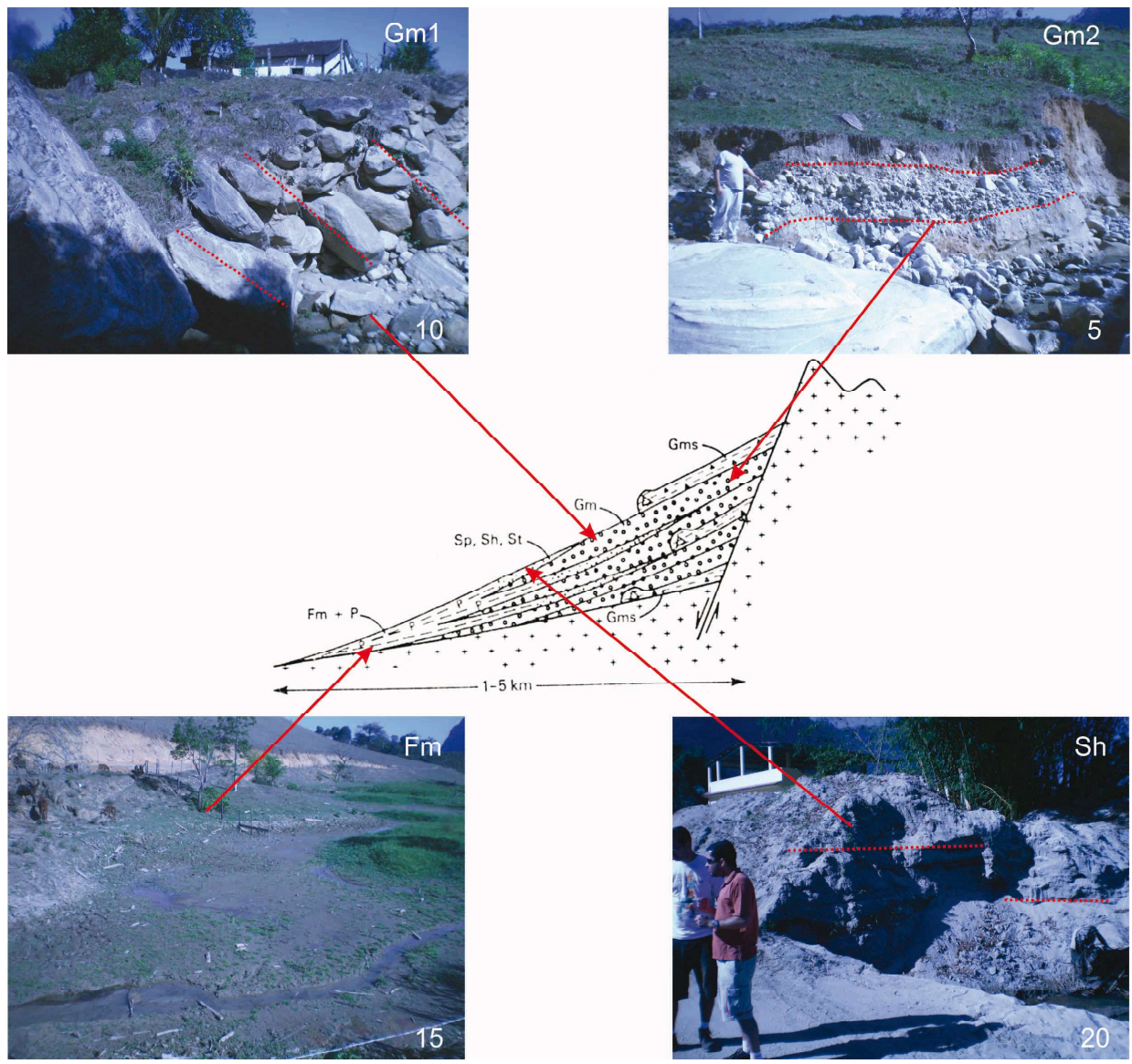

Figura 8 - Fácies sedimentares distintivas de leque aluvial (descrição na tabela 2). As posições aproximadas são indicadas no perfil longitudinal esquemático de leques aluviais proposto por Rust \& Koster (1984). Os números têm equivalência com os pontos mais notáveis descritos na tabela 1. Sua distribuição espacial pode ser conferida nas figuras 3 e 6. 
Tabela 2: Descrição sucinta das fácies sedimentares apresentadas nas figuras 7 e 8. Compilação elaborada a partir de Rust \& Koster (1984).

\begin{tabular}{c|c}
\hline Fácies & Descrição \\
\hline $\mathrm{D}$ & $\begin{array}{c}\text { Fluxo de detritos: Pacotes com baixa maturidade textural e composicional. Sedimentação } \\
\text { caótica, em rampas de alta declividade, típica de ambiente francamente proximal. }\end{array}$ \\
\hline $\mathrm{Gm} 1$ & $\begin{array}{c}\text { Pacotes cascalhosos, suportados pelo arcabouço, com clastos imbricados. Ambiente } \\
\text { proximal a intermediário. }\end{array}$ \\
\hline $\mathrm{Gm} 2$ & $\begin{array}{c}\text { Pacotes cascalhosos, suportados pelo arcabouço, com acamamento sub-horizontal } \\
\text { incipiente. Ambiente proximal a intermediário. }\end{array}$ \\
\hline $\mathrm{Sh}$ & Pacotes arenosos com acamamento sub-horizontal. Ambiente intermediário a distal. \\
\hline $\mathrm{Fm}$ & Lama ou lama arenosa maciça (sem estruturas planares). Ambiente francamente distal. \\
\hline
\end{tabular}

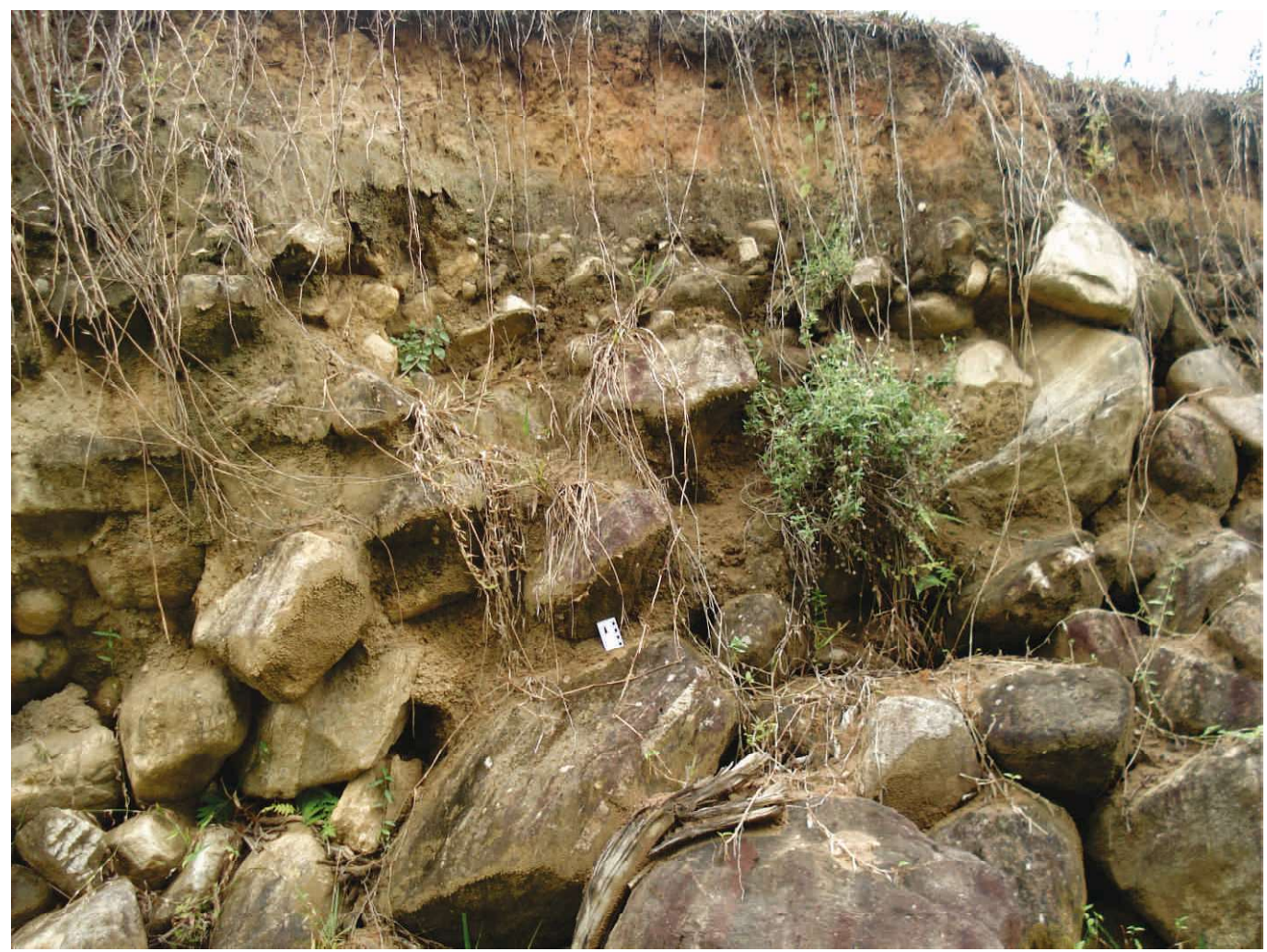

Figura 9 - Depósito exposto na porção intermediária do leque de São Vicente. Atentar para a parte central do pacote, exibindo gradação normal, típica dos fluxos fluidificados em lençol.

\section{Análise e Discussão dos Resultados}

De acordo com Assine (2008), os leques aluviais podem ser classificados como: leques dominados por fluxo de gravidade ou leques fluviais. Algumas características observadas no leque aluvial de São Vicente permitem que ele seja enquadrado na primeira classe, quais sejam:

a) dimensão longitudinal pequena a média (poucos quilômetros); b) geração a partir da interação entre processos gravitacionais e fluviais e;

c) declividade relativamente alta (superior a $10 \%$ na zona proximal).

No que diz respeito à morfologia, com a espacialização do leque foi possível perceber que não se trata de um corpo morfossedimentar lobado. Como o eixo longitudinal é significativamente maior que o transversal (Figuras 3 e 6), também é possível constatar 
que sua geometria é assimétrica. Estas características morfológicas fogem das expectativas sintetizadas em Assine (2008): os leques aluviais apresentam dois eixos com dimensões relativamente similares e só recebem este nome em função do formato em "saia", exibido em planta (Figura 10).

Além da forte assimetria, as cabeceiras do leque aluvial de São Vicente apresentam indícios de alimentação radial, a partir de múltiplas rampas menores, sem vínculo com drenagens ativas. Estas rampas coalescem junto ao corpo d'água perene que drena toda a área (Figura 11).

bacia de drenagem ou área de captação
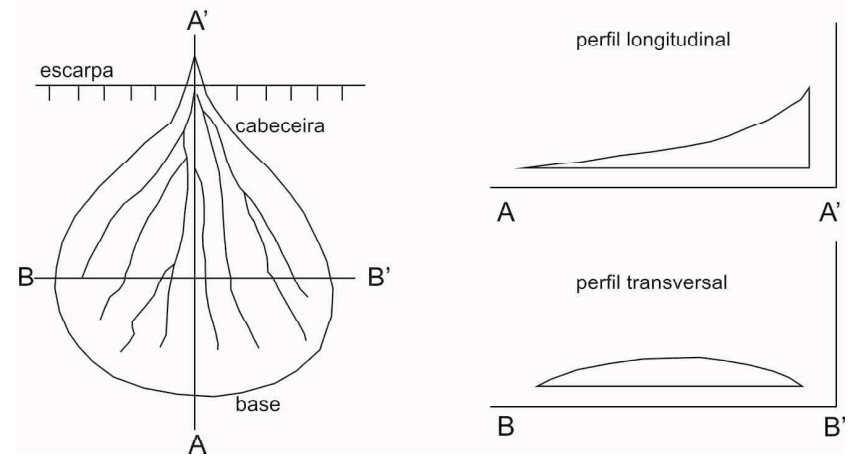

Figura 10 - Perfis topográficos em leques aluviais. Modificado de Assine (2008).
A presença de diversas rampas menores junto à cabeceira mostra que o leque de São Vicente também contraria a tendência de que leques aluviais são edificados a partir de suprimentos sedimentares provenientes de fonte única, confinada em um vale estreito e relativamente profundo, localizado na extremidade a montante. Com base nisso, pode-se dizer que, além da forma não lobada e fortemente assimétrica, a alimentação múltipla consiste em mais um ponto no qual o leque aluvial de São Vicente diverge da expectativa mais comum para leques aluviais dominados por fluxos de gravidade, apresentada na figura 12 .

\section{Conclusões e Recomendações}

Com base nos dados geomorfológicos e estratigráficos levantados, o leque aluvial de São Vicente pode de fato ser classificado como um leque aluvial dominado por fluxo de gravidade. No entanto, conforme demonstrado no capítulo anterior, os processos envolvidos em sua gênese não podem ser plenamente explicados pelos elementos apresentados nos blocos-diagrama da literatura especializada (p. ex. Assine, 2008).

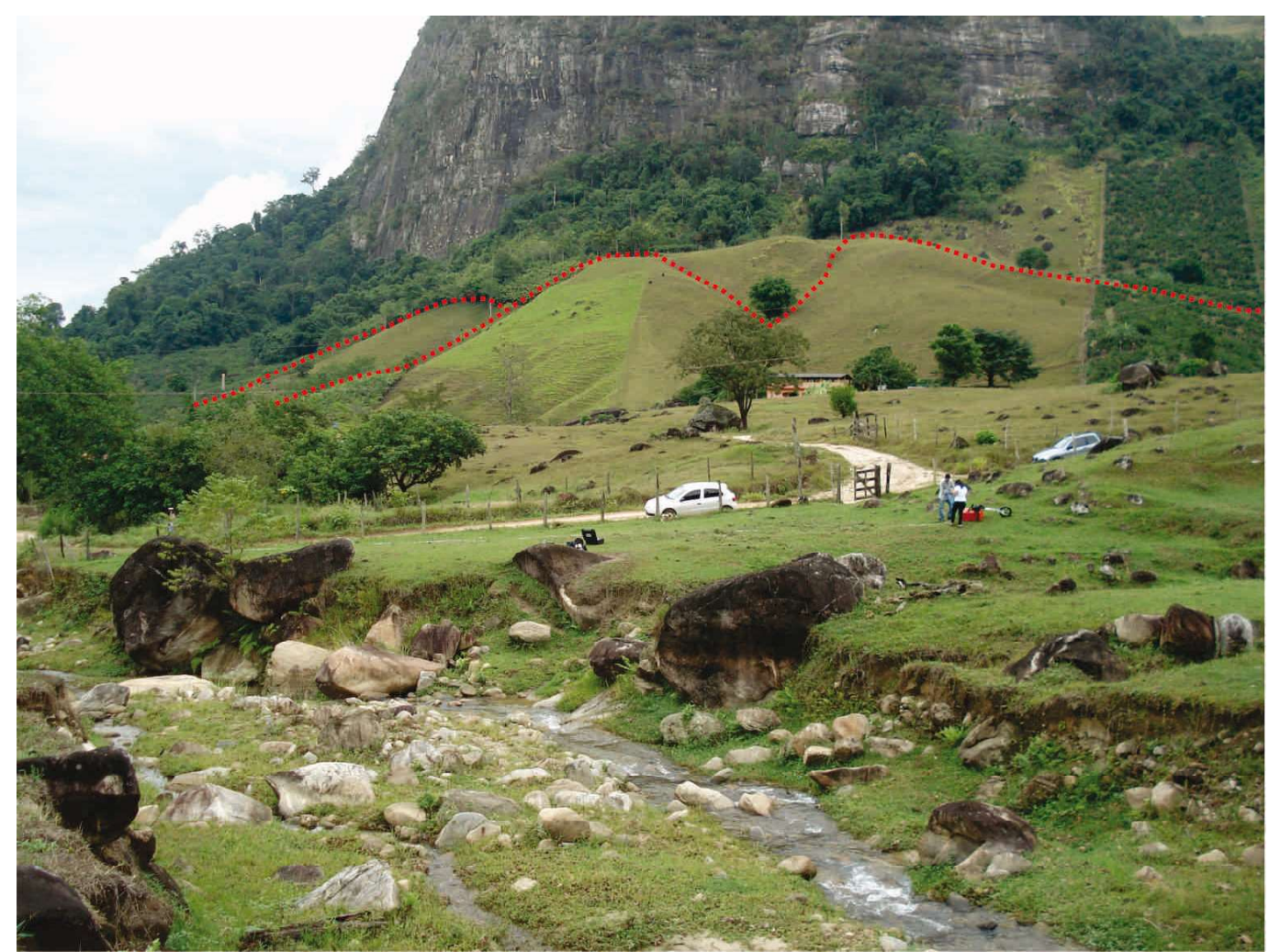

Figura 11 - Leques aluviais menores na cabeceira noroeste do leque de São Vicente. Destaque para a parte inferior da fotografia, onde pode ser observado o retrabalhamento da zona de coalescência dos leques pela drenagem perene. 


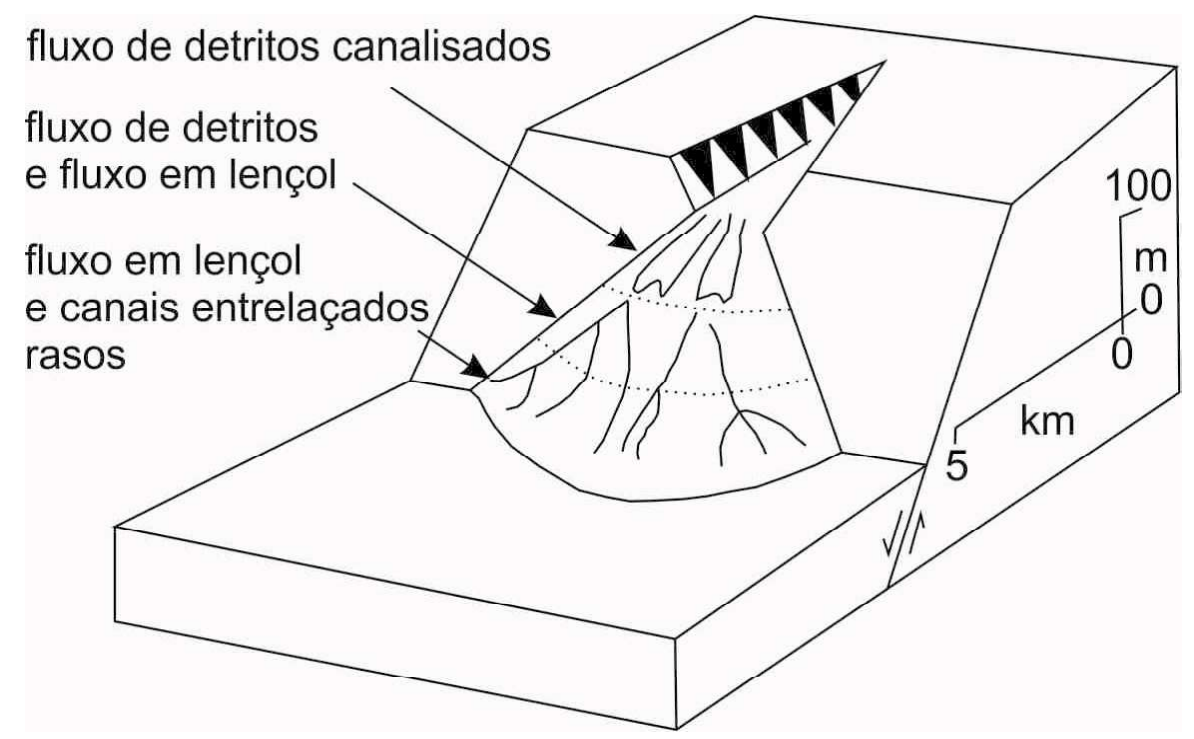

Figura 12 - Modelo de leque aluvial dominado por fluxo de gravidade. Modificado de Assine (2008).

Tendo em vista algumas particularidades morfossedimentares da região de São Vicente, tais como o confinamento triangular das cabeceiras, desencadeando um suprimento radial de sedimentos, a classificação do leque de São Vicente pode ser refinada, de forma que se possa também considerá-lo um leque aluvial secundário, de acordo com as concepções de Denny (1967) e Heward (1978). A feição sedimentar principal seria, neste caso, produto do retrabalhamento progressivo de leques primários, cujos resquícios dominam a porção mais proximal da área de estudo (Figura 13).
De acordo com Assine (2008) normalmente a formação de leques secundários está associada à umidificação do clima após uma fase árida, levando ao aumento da energia hidráulica e erosão de leques primários, com formação de canais entrincheirados. Outra possibilidade seriam eventos tectônicos, condicionando a movimentação diferencial de blocos e os consequentes fenômenos de entricheiramento e alimentação de leques mais jovens.

Quando se considera que os leques primários da região de São Vicente são radiais (Figura 12), desprovidos de drenagens perenes e nitidamente marcados por
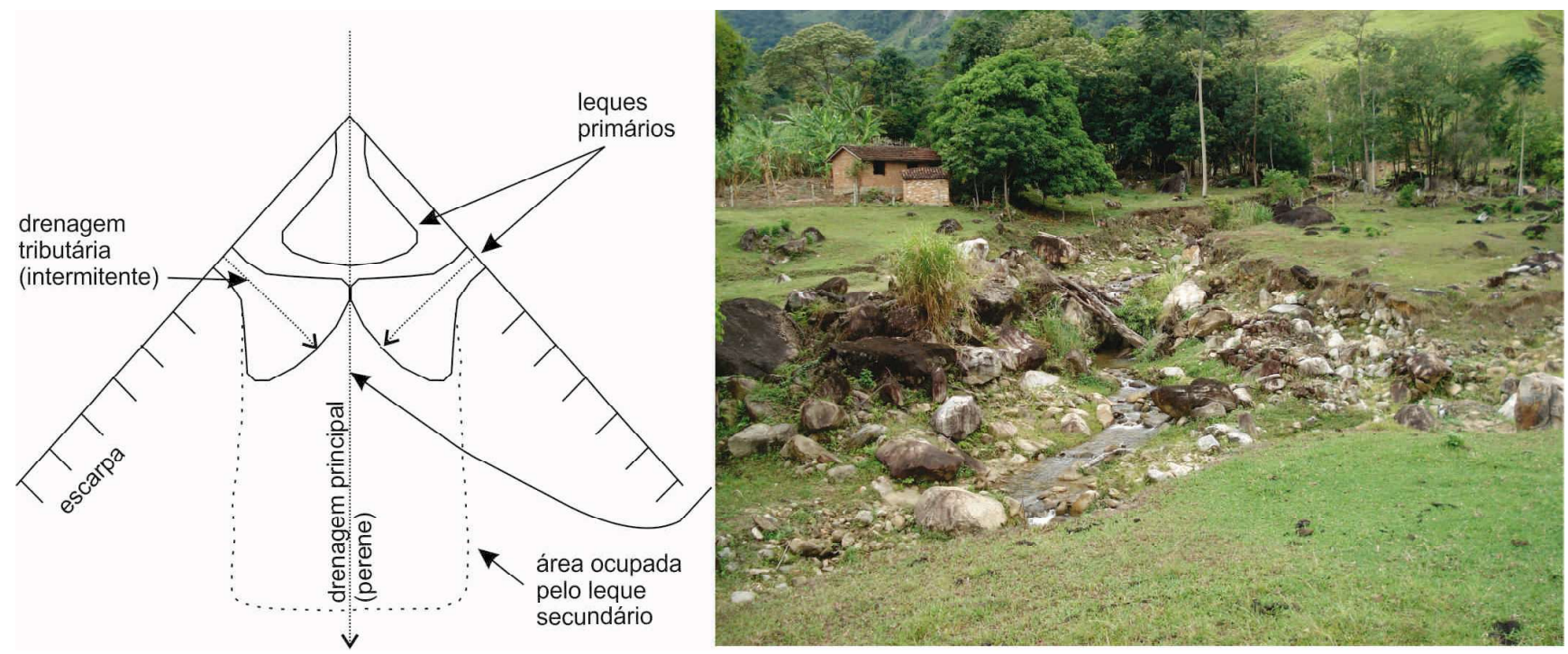

Figura 13 - Diagrama ilustrando a evolução do leque aluvial de São Vicente a partir do retrabalhamento de leques menores localizados em sua porção mais a montante. 
alta declividade e sedimentação proximal, descarta-se a hipótese de um evento da envergadura de uma oscilação climática. Na região investigada não há qualquer possibilidade de escoamento sedimentar até base do leque principal que não a partir do retrabalhamento dos leques primários pela drenagem perene, independente das condições climáticas vigorantes. Entretanto, vale destacar que uma corrida como a de 2009 certamente foi condicionada pela fluidificação dos leques primários, tendo em vista a intensidade e persistência anormal das chuvas, fato relatado com ênfase por moradores que já haviam presenciado eventos análogos no passado.

Com base no contexto estrutural regional, é possível inferir que os lineamentos definidos pelas linhas de cumeada das escarpas que confinam o leque (Figuras 3 , 4 e 6) se relacionam a estruturas subparalelas ao traço NE-SW da falha de empurrão apresentada na figura 2. De maneira semelhante, acredita-se que a inflexão da escarpa noroeste, notada junto à linha limítrofe entre as porções proximal e distal do leque, esteja relacionada à deformação transcorrente (Figura 2).

No que concerne ao uso e ocupação, sugere-se que o poder público acompanhe com atenção todas as iniciativas de loteamento das imediações do leque, tendo em vista o risco/susceptibilidade de ocorrência de eventos similares no futuro. Neste sentido, os limites cartográficos da área de influência do leque se prestam como material de apoio ao gerenciamento fundiário da região.

Com respeito às questões ambientais, é perceptível que a região sofreu o processo de supressão localizada da vegetação nativa, com consequente substituição por pastagens e pela cultura de café. Este fato se deu principalmente sobre as zonas de coalescência dos leques primários, aproveitando áreas de menor declividade. Apesar disso, as proporções da corrida em termos de área afetada e volume de material transportado, com efeitos notáveis sobre o rearranjo tridimensional de pacotes sedimentares pré-existentes, denota a irrelevância de qualquer interferência antrópica superficial sobre a disparada do evento convulsivo.

Durante a realização dos trabalhos de campo, vários moradores relataram a ocorrência de fortes ruídos, precedendo o início da corrida. Num primeiro momento, imaginou-se que pudessem se tratar de pequenos sismos associados ao reajuste de estruturas frágeis. Entretanto, tendo em vista que outro conjunto de moradores afirmou ter ouvido os ruídos durante todo o curso do evento, acredita-se que se trate do choque entre blocos ao longo do transporte vertente abaixo, uma vez que a fluidificação dos depósitos pré-existentes seria capaz de disparar o evento convulsivo independentemente da ocorrência de sismos associados.

\section{Referências Bibliográficas}

ASSINE, M. L. Ambientes de Leques Aluviais. In: Silva, A. J. C. L.; ARAGÃO, M. A. N. F.; MAGALHÃES, A. J. C. Ambientes de Sedimentação Siliciclástica do Brasil. São Paulo: Beca, 2008 , p. $53-71$.

CPRM. Cachoeiro de Itapemirim - Folha SF-24-V-A-V. [Brasília], 1993. 1 mapa. Escala: 1:100.000.

DENNY, C. S. Fans and Pediments. American Journal of Science. n. 265, p. 81 - 105. 1967.

IBGE. Cachoeiro de Itapemirim - Folha SF-24-V-A-V-4. [Rio de Janeiro], 1978. 1 mapa. Escala: 1:50.000.

GATTO, L. C. S. et al. Geomorfologia. In: Projeto Radambrasil. Folhas SF 23 e 24 - Rio de Janeiro e Vitória. Rio de Janeiro: IBGE, 1983, p. $305-384$.

HARVEY, A. M.; MATHER, A. E.; STOKES, M. (eds). Alluvial Fans: Geomorphology, Sedimentology, Dynamics. London: The Geological Society of London (Special Publication n. 251), 2005, 248 p.

HEWARD, A. P. Alluvial Fan Sequence and Megasequence Models. In: Miall, A. D. (ed.). Fluvial Sedimentology. Calgary: Canadian Society of Petroleum Geologists, 1978, p. 669 - 702.

KING, L. C. A. Geomorfologia do Brasil Oriental. Rev. Bras. Geogr., Rio de Janeiro, v. 18, n. 2, p. 147-265, 1956.

LANA, C. E.; CERQUEIRA, F. C.. Eventos Convulsivos e a Perda de Equilíbrio em Ecossistemas Lóticos no Sul do Estado do Espírito Santo. In: Simpósio de Geologia do Sudeste, XI, 2009, São Pedro. Anais..., 2009.

LANA, C. E. et al.. Análise Morfo-sedimentar do Leque Aluvial de São Vicente (Cachoeiro de Itapemirim - ES), com ênfase no Evento Convulsivo de 2009 e Impactos Relacionados. In: Simpósio de Geologia do Sudeste, 12, 2011, Nova Friburgo. Anais..., 2011.

LOWE, D. R. Sediment Gravity Flows: Their Classification and Some Problems of Aplication to Natural Flows and Deposits. In: DOYLE, L. J./ PILKEY, O. H. (eds.). Geology of Continental Slopes. Tulsa: Society of Economic Paleontologists and 
Mineralogists (Special Publication 27), p. 75 - 82.

MACEDO, R. S. et al. Estudo da Evolução Morfossedimentar do Leque Aluvial de São Vicente (Cachoeiro de Itapemirim ES) com base em Mapeamento Planialtimétrico, Modelagem Tridimensional, Perfis Estratigráficos e Seções de Radar de Penetração no Solo. In: Congresso Brasileiro de Geologia, 46, 2012, Santos. Anais..., 2012.

MIALL, A. D. Lithofacies Types and Vertical Profile Models of Braided River Deposits, a Summary. In: (ed.). Fluvial

Sedimentology. Calgary: Canadian Society of Petroleum Geologists, 1978, p. 597 - 604.

Principles of Sedimentary Basin Analysis. 2nd. ed. Berlin: Springer, 1990, 668 p.
MIRANDA, E. E. de (coord.). Brasil em Relevo. Campinas: Emprapa Monitoramento por Satélite, 2005. Disponível em: $<$ http://www.relevobr.cnpm.embrapa.br $>$. Acesso em: 6 de maio de 2015.

RUST, B. R. The Cannes de Roche Formation: Carboniferous Alluvial Deposits in Eastern Gaspé, Canada. In: Geldsetzer, H. H.J. (ed.). Atlantic Coast Basins. Paris: Compte Rendu (International Carboniferous Congress), 1984, n. 3, p. 72 - 84.

RUST, B. R.; KOSTER, E. H. Coarse Alluvial Deposits. In: WALKER, R. G. (ed.). Facies Models. Hamilton: Geoscience Canada, 1984, p. 53 - 69.

WALKER, R. G. (ed.). Facies Models. Hamilton: Geoscience Canada, 1984, 317 p. 